\title{
Epidemiological study of HER-2 mutations among EGFR wild-type lung adenocarcinoma patients in China
}

\author{
Xuefei $\mathrm{Li}^{1+}$, Chao Zhao ${ }^{1 \dagger}$, Chunxia Su${ }^{2}$, Shengxiang Ren², Xiaoxia Chen ${ }^{2}$ and Caicun Zhou ${ }^{2 *}$
}

\begin{abstract}
Background: Human epidermal growth factor receptor (HER)-2 is a driver gene in non-small cell lung cancer (NSCLC). The present study evaluated the mutation rate of HER-2 within the wild-type epidermal growth factor receptor (EGFR) lung adenocarcinoma population in China.
\end{abstract}

Methods: Formalin-fixed, paraffin-embedded samples from 456 patients with wild-type EGFR lung adenocarcinoma were analyzed for HER-2 mutations by amplification-refractory mutation system (ARMS), and HER-2 protein expression was evaluated by immunohistochemistry. All samples positive for HER-2 mutation underwent direct sequencing for further verification.

Results: HER-2 mutation was detected in 22/456 cases (4.8\%); the rate was $6.7 \%$ among 331 triple-negative samples (i.e., wild-type EGFR, anaplastic lymphoma kinase, and ROS proto-oncogene 1). Direct sequencing confirmed that the results were consistent with those obtained by ARMS analysis in 19 cases. The positive rate was $15.4 \%$ by immunohistochemical analysis of HER-2 expression; this was not correlated with mutation rate. HER-2 mutation and positivity were not correlated with gender, age, smoking status, disease stage, or histological subtype. The 22 cases of HER-2 mutations occurred only in acinar (36.4\%), papillary (36.4 \%), minimally invasive (13.6 \%), solid (9.2\%), and invasive mucinous (4.5\%) subtypes. Disease-free and overall survival were not associated with HER-2 mutation or HER-2 protein overexpression.

Conclusion: The HER-2 mutation rate was $4.8 \%$ among EGFR wild-type lung adenocarcinoma patients in China, and $6.7 \%$ among driver genes, triple-negative lung adenocarcinoma. The incidence of HER-2 mutation varied among different lung adenocarcinoma subtypes, occurring mainly in acinar and papillary predominant subtypes. $15.4 \%$ of EGFR wild-type lung adenocarcinoma patients showed HER-2 protein overexpression, but this was not correlated to HER-2 mutation. Existing follow-up data did not show a correlation between HER-2 mutation with DFS or OS.

Keywords: HER-2, ALK, ROS1, Lung adenocarcinoma

\footnotetext{
* Correspondence: caicunzhoudr@163.com

${ }^{\dagger}$ Equal contributors

${ }^{2}$ Department of Medical Oncology, Shanghai Pulmonary Hospital, Tongji

University Medical School Cancer Institute, Tongji University School of

Medicine, No. 507 Zhengmin Road, Shanghai 200433, People's Republic of

China

Full list of author information is available at the end of the article
} 


\section{Background}

Human epidermal growth factor receptor (HER)-2 is a member of the epidermal growth factor receptor (EGFR) family, in which it is considered as having the highest activity. HER-2 forms heterodimers with other family members to activate downstream mitogen-activated protein kinase and phosphoinositide 3-kinase/Akt signaling pathways [1-4]. Somatic mutations have been identified within the kinase domain of HER-2 [5]; the HER-2 mutation rate in non-small cell lung cancer (NSCLC) is $2 \%-4 \%$ [6-8]. However, the relationship between HER-2 mutation and the clinical characteristics and prognosis of lung adenocarcinoma remains unclear, not least because of inconsistencies among findings reported by various studies. For example, some studies have shown that HER-2 mutations were prevalent among non-smoking Asian females [9-11], while another found that HER-2 mutation was related to disease stage [12]. HER-2 protein was overexpressed in $13 \%-20 \%$ of NSCLC patients [11]; a strong positive expression (i.e., immunohistochemistry score of 3+) was observed in $2 \%-6 \%$ of cases $[12,13]$. HER-2 overexpression has also been linked to poor patient prognosis [14-16].

The present study investigated the HER-2 mutation rate in lung adenocarcinoma patients in China with wild-type EGFR and its relationship to clinical characteristics and prognosis.

\section{Methods}

\section{Patients and study design}

The inclusion criteria were as follows: patients over 18 years old; confirmed diagnosis of lung adenocarcinoma; wild-type EGFR gene; Eastern Cooperative Oncology Group score of 0-2 points; sufficient formalin-fixed, paraffin-embedded samples for HER-2 mutation detection and DNA sequencing; and patient who did not receive preoperative neoadjuvant therapy. Exclusion criteria were as follows: patients with other tumors or severe diseases, including psychiatric illnesses; and pregnancy. The study protocol was approved by the Ethical Review Committee of the Shanghai Pulmonary Hospital, and the clinical registration number was ChiCTR-OCH13003507. The study design is outlined in Fig. 1.

\section{Detection of EGFR, anaplastic lymphoma kinase (ALK), ROS proto-oncogene (ROS) 1, and HER-2 mutations}

A DNA/RNA Isolation kit (Amoy Diagnostics Co., Xiamen, China) was used according to the manufacturer's instructions to extract DNA from formalin-fixed, paraffin-embedded tissue samples. Mutations were detected using the Human EGFR Mutation, Human echinoderm microtubule-associated protein-like 4-ALK Fusion Gene, Human ROS1 Fusion Gene, and Human HER-2 Mutation Detection kits (Amoy Diagnostics Co.). PCR amplification conditions were as follows: $95{ }^{\circ} \mathrm{C}$ 5 min; 15 cycles of $95{ }^{\circ} \mathrm{C}$ for $25 \mathrm{~s}$ and $72{ }^{\circ} \mathrm{C}$ for $20 \mathrm{~s}$; and 31 cycles of $93{ }^{\circ} \mathrm{C}$ for $25 \mathrm{~s}, 60{ }^{\circ} \mathrm{C}$ for $35 \mathrm{~s}$, and $72{ }^{\circ} \mathrm{C}$ for $20 \mathrm{~s}$. All samples positive for HER-2 mutations were confirmed by DNA sequencing using primers with the following sequences: 5'GCC ATG GCT GTG GTT TGT GAT GG3' (forward) and 5'ATC CTA GCC CCT TGT GGA CAT AGG3', which amplified a 342-bp fragment in exon 20 of the HER-2 gene.

\section{Immunohistochemistry}

HER-2 expression in tissue was detected using a rabbit monoclonal anti-HER-2/Erbb2 (29D8) antibody (diluted 1:200) (Cell Signaling Technology, Danvers, MA, USA). The intensity of the signal was determined as previously described [10], which was as follows: 0 , no staining; $1+$, $<5 \%$ of cells with strong staining or $5 \%-10 \%$ of cells

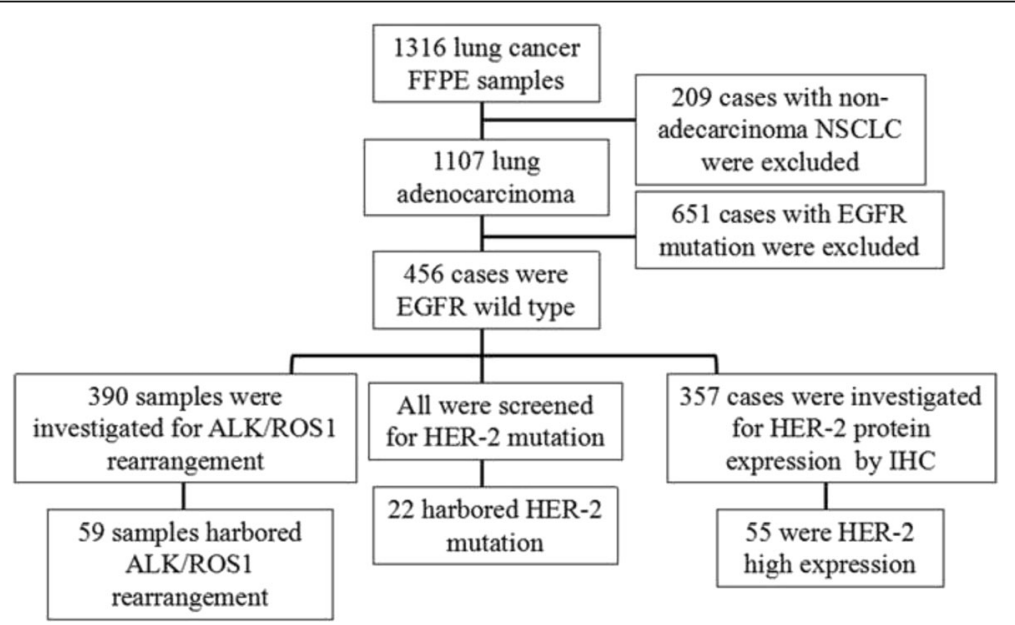

Fig. 1 Study design. 456 cases with EGFR wild type were screened from 1316 patients and enrolled in this study 
with weak staining; $2+, 5 \%-10 \%$ of tumor cells with strong staining or $>10 \%$ of tumor cells with weak staining; and $3+,>10 \%$ of cells with strong staining. Membranous staining was set as the criteria, and cytoplasmic staining was excluded from the scoring of stain intensity. Scores of $0 / 1+$ and $2+/ 3+$ were counted as negative and positive HER-2 expression, respectively. Samples were independently evaluated by two pathologists.

\section{Statistical analysis}

SPSS v.17.0 software (SPSS Inc., Chicago, IL, USA) was used for statistical analysis. Disease-free survival (DFS) was defined as the time between the start of surgery to the first recorded disease recurrence/metastasis. Overall survival (OS) was defined as the time between the start of surgery to disease-related death. The correlations between HER-2 mutation and clinical characteristics, as well as between HER-2 mutation and protein expression, were evaluated with Pearson's $X^{2}$ test or Fisher's exact test. Survival was analyzed with the Kaplan-Meier test, and survival comparisons were carried out with the log-rank test. The two-sided significance level was set at $P<0.05$.

\section{Results}

\section{Patient characteristics}

Patient characteristics are summarized in Table 1. A total of 1316 formalin-fixed, paraffin-embedded samples from surgical patients at Shanghai Pulmonary Hospital were initially screened, including 1107 cases of lung adenocarcinoma, of which 456 wild-type EGFR lung adenocarcinoma cases were analyzed for HER-2 mutation. The final sample set included 250 males and 206 females; the median age was 60 years (range: 26-82 years), with 135 and 321 cases $\geq 65$ and $<65$ years, respectively. In addition, 295 patients had never smoked or were light smokers while 161 were heavy smokers. In terms of disease staging, 262 cases were Stage I, 46 were Stage II, 91 were Stage III, 23 were Stage IV, and 34 were unconfirmed. The 437 cases were classified according to lung adenocarcinoma subtype based on the 2011 criteria. There were 40 cases of lepidic predominant adenocarcinoma (LPA), 187 of acinar predominant adenocarcinoma (APA), 100 of papillary predominant adenocarcinoma (PPA), 35 of solid predominant adenocarcinoma (SPA), 31 of invasive mucinous adenocarcinoma (IMA), 14 of adenocarcinoma in situ (AIS), 14 of minimally invasive adenocarcinoma

Table 1 Characteristics of patients with wild-type or mutant HER-2 and positive or negative HER-2 expression by immunohistochemistry

\begin{tabular}{|c|c|c|c|c|c|c|c|}
\hline & & HER-2 WT n(\%) & HER-2 MUT n(\%) & $p$ value & HER-2 IHC(-) n(\%) & HER-2 IHC(+) n(\%) & $p$ value \\
\hline \multirow[t]{2}{*}{ Sex } & Male & $239(55.1)$ & $11(50.0)$ & 0.666 & $162(53.6)$ & $30(54.5)$ & 1.000 \\
\hline & Female & 195(44.9) & $11(50.0)$ & & $140(46.4)$ & $25(45.5)$ & \\
\hline \multirow[t]{2}{*}{ Age } & $\geq 65$ & 132(30.4) & $3(13.6)$ & 0.100 & $80(26.5)$ & $21(38.2)$ & 0.103 \\
\hline & $<65$ & $302(69.6)$ & 19(86.4) & & $222(73.5)$ & $34(61.8)$ & \\
\hline \multirow[t]{2}{*}{ Smoking status } & Never/light smoking & $280(64.5)$ & $15(68.2)$ & 0.822 & 190(62.9) & $40(72.7)$ & 0.172 \\
\hline & Smoking & $154(35.5)$ & $7(31.8)$ & & 112(37.1) & $15(27.3)$ & \\
\hline \multirow[t]{4}{*}{ Disease stage } & । & $249(62.3)$ & 13(59.1) & 0.619 & 184(66.9) & $31(62.0)$ & 0.887 \\
\hline & $\|$ & $43(10.8)$ & $3(13.6)$ & & $27(9.8)$ & $5(10.0)$ & \\
\hline & III & $85(21.3)$ & $6(27.3)$ & & $52(18.9)$ & $12(24.0)$ & \\
\hline & IV & $23(5.8)$ & $0(0.0)$ & & $12(4.4)$ & $2(4.0)$ & \\
\hline \multirow[t]{9}{*}{ Histologic subtype } & Lepidic & $40(9.6)$ & $0(0.0)$ & 0.436 & $34(11.5)$ & $3(5.8)$ & 0.166 \\
\hline & Acinar & 179(43.1) & $8(36.4)$ & & $126(42.7)$ & $20(38.5)$ & \\
\hline & Papillary & $92(22.2)$ & $8(36.4)$ & & $57(19.3)$ & $12(23.1)$ & \\
\hline & Micropapillary & $14(3.4)$ & $0(0.0)$ & & $12(4.1)$ & $1(1.9)$ & \\
\hline & Solid & $33(8.0)$ & $2(9.1)$ & & $20(6.8)$ & $8(15.4)$ & \\
\hline & IMA & $28(6.7)$ & $3(13.6)$ & & $24(8.1)$ & $4(7.7)$ & \\
\hline & Enteric & $2(0.5)$ & $0(0.0)$ & & $1(0.3)$ & $1(0.2)$ & \\
\hline & AIS & $14(3.4)$ & $0(0.0)$ & & $12(4.1)$ & $0(0.0)$ & \\
\hline & $\mathrm{MIA}$ & $13(3.1)$ & $1(4.5)$ & & $9(3.1)$ & $3(5.8)$ & \\
\hline
\end{tabular}

The total number of wild-type and mutant HER-2 cases was 456; disease stage and histologic subtype data were available for 422 and 437 of these cases, respectively

The total number of cases negative or positive for HER-2 by immunohistochemistry was 357; disease stage and histologic subtype data were available for 325 and 347 cases, respectively

Abbreviations: AIS adenocarcinoma in situ, IMA invasive mucinous adenocarcinoma, MIA minimally invasive adenocarcinoma 
(MIA), 14 of micropapillary predominant adenocarcinoma (MPA), and two of enteric adenocarcinoma (EA).

\section{HER-2 mutation rate}

ARMS analysis was used to detect HER-2 exon 20 mutations in 456 cases of wild-type EGFR lung adenocarcinoma; $22(4.8 \%)$ were found to be positive. The presence of an echinoderm microtubule-associated protein-like 4/ anaplastic lymphoma kinase (ALK)-ROS proto-oncogene (ROS) 1 fusion gene was also examined in 390 cases; 331 were found to harbor wild-type ALK/ROS1. The HER-2 mutation rate in patients with wild-type EGFR/ALK/ ROS1 (i.e., triple-negative samples) was $6.7 \%$; the 22 samples were analyzed by PCR combined with direct sequencing. For three of the samples, sequencing failed due to insufficient sample quantity. Results for the remaining 19 samples were consistent with those obtained by ARMS: 13 cases were 2324_2325 ins12 (atacgtgatggc), three were 2326_2327insTGT, two were 2325_2326 ins12 (tacgtgatggct), and one was 2331_2332 ins9 (ggctcccca) (Fig. 2).

\section{Analysis of HER-2 protein expression}

HER-2 protein expression was assessed in 357 samples by immunohistochemistry. Results were interpreted as previously described [10]. There were 55 positive samples $(15.4 \%)$, of which 43 were $2+(12.0 \%)$ and 12 were $3+(3.4 \%)$ (Fig. 3).
Relationship between HER-2 mutation and protein expression and clinical characteristics

The presence of $H E R-2$ mutations was not correlated with clinical characteristics, including gender, age, smoking status, histological subtype, and disease stage. However, the mutation rate differed among lung adenocarcinoma subtypes: the 22 cases of HER-2 mutation were observed in APA (36.4 \%), PPA (36.4 \%), MIA (13.6\%), SPA (9.2\%), and IMA (4.5\%), whereas no mutations were detected in LPA, MPA, EA, or AIS (Table 1 and Fig. 4). Furthermore, there was no correlation between HER-2 mutation and protein expression. Simultaneous HER-2 mutation and HER-2 overexpression was observed in only two samples.

\section{Relationship between prognosis and HER-2 mutation or protein expression}

At the last follow-up, 123 patients achieved DFS, and OS data were collected from 39 patients. Most of the remaining patients continued to survive, and follow-up data are needed. A subset of patients was lost to followup. HER-2 mutation was not associated with DFS (median: 16.7 vs. 17.0 months; $\mathrm{P}=0.966$ ). The difference with $\mathrm{OS}$ was also not statistically significant (median: 34.2 vs. 47.6 months; $\mathrm{P}=0.844$ ). DFS data were obtained from 79 and 17 patients who were negative and positive for HER-2, respectively, by immunohistochemistry. However, DFS did not differ significantly between the two groups (median: 14.4 vs. 12.8 months, $\mathrm{P}=0.238$ ). The 14 HER-2-negative and one HER-2-positive patients

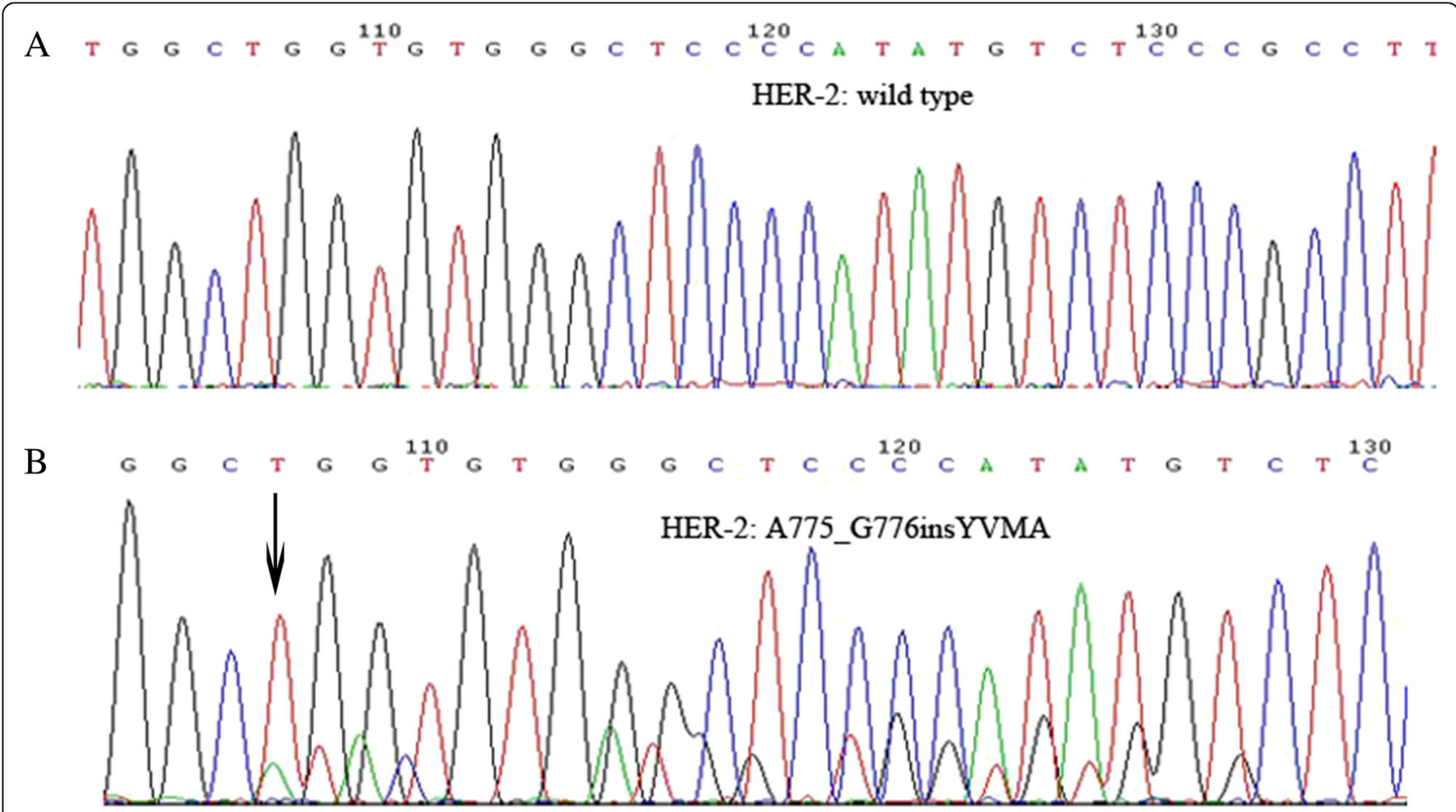

Fig. 2 The confirmed results of HER-2 mutations by DNA sequencing. a HER-2 wild type; b The arrow showed HER-2 A755_G776insYVMA 


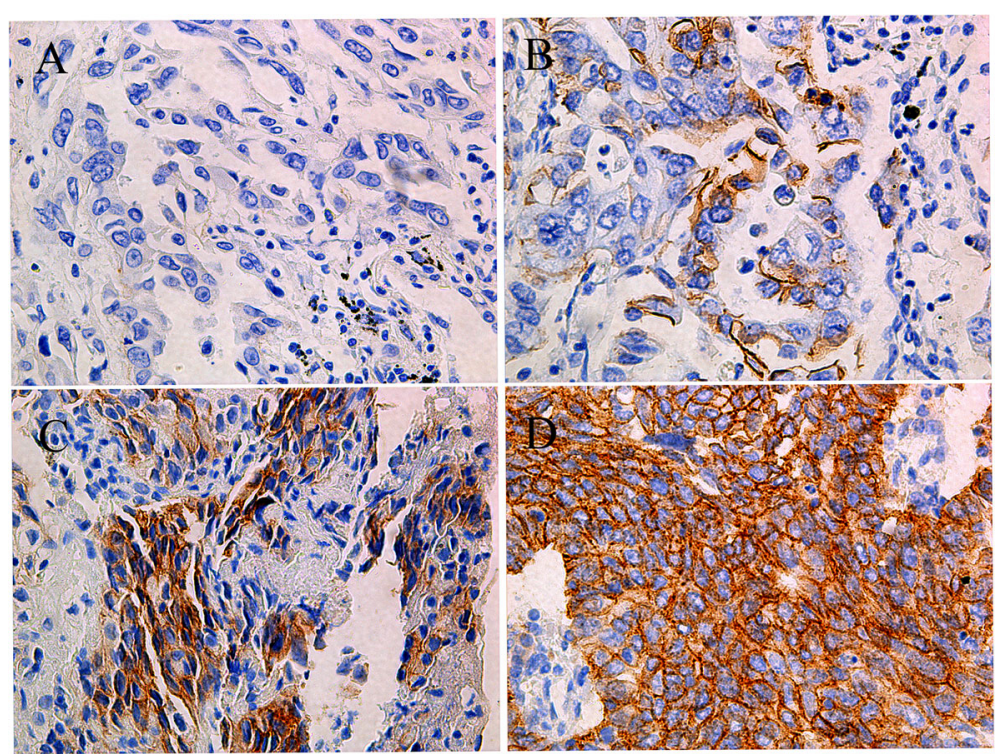

Fig. 3 HER-2 protein expression in EGFR wild type lung adenocarcinoma patients by immunohistochemistry: A.0 B.1+ C.2+ D.3+

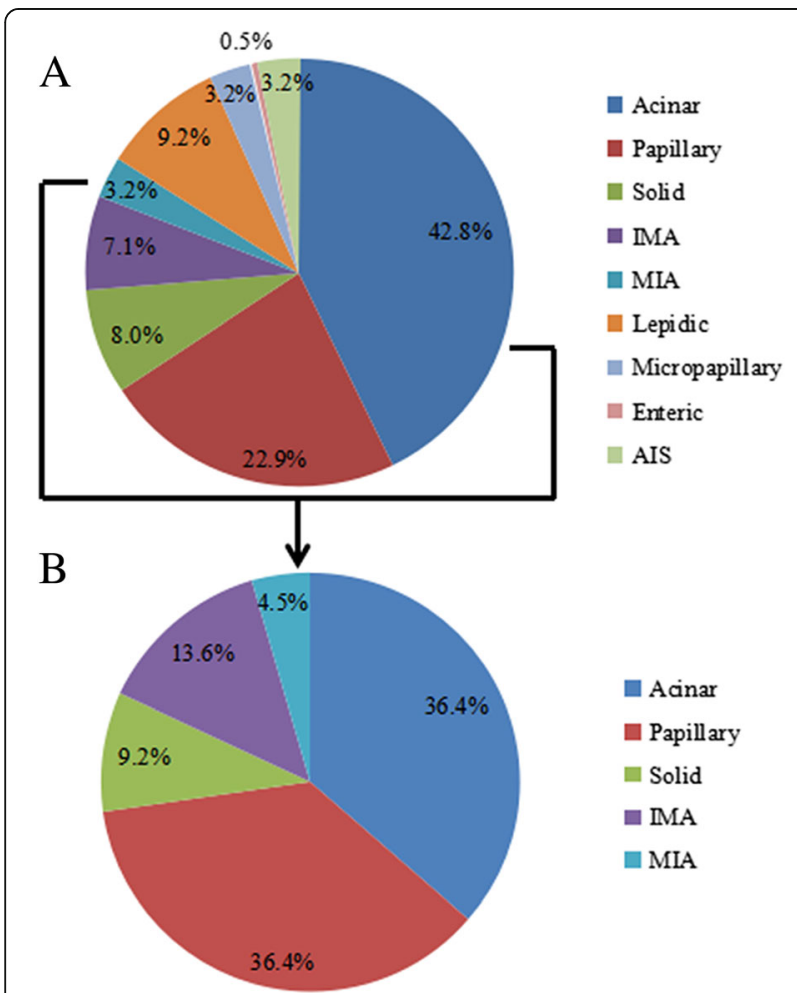

Fig. 4 Histologic subtype distribution of the 437 EGFR wild type and 22 HER-2 mutation samples. a Acinar and papillary are the most common histologic subtypes in lung adenocarcinoma; b HER-2 mutations occurred in acinar, papillary, solid, IMA, and MIA subtypes, other subtypes were not found (IMA, invasive mucinous adenocarcinoma; MIA, minimally invasive adenocarcinoma) had similar OS (median: 24.9 vs. 48.0 months, $\mathrm{P}=0.075$ ) (Fig. 5). We also analyzed the DFS data of the HER2 IHC(-) versus HER2 IHC (+) in stage I/II and stage III/IV cases, respectively (Additional file 1: Figure S1) and found that none of them had a significantly difference.

\section{Discussion}

In the present study, HER-2 mutation rate and protein expression level were measured in 456 patients with wildtype EGFR lung adenocarcinoma. The HER-2 mutation rate was $4.8 \%$ while the rate in EGFR/ALK/ROS1 triplenegative samples was $6.7 \%$. There was no correlation between HER-2 mutation and clinical characteristics. The rate differed according to lung adenocarcinoma subtype and was highest in APA (36.4 \%) and PPA (36.4\%).

HER-2 mutations have been linked to NSCLC. Other studies have shown that they also occur in lung adenocarcinoma, with mutation rates from $2 \%$ up to $14.1 \%[9,10$, 17]. Our results were consistent with previous studies reporting a HER-2 mutation rate of $1.98 \%$ in the overall population, $4.8 \%$ in wild-type EGFR cases, and $6.7 \%$ in EGFR/ALK/ROS1 triple-negative cases. The most commonly observed HER-2 mutation is an in-frame insertion in exon 20 [6]. An analysis of HER-2 mutations in exons 18-21 identified cases harboring the same exon 20 insertion [10]. In the present study, DNA sequencing of 19 patients revealed 15 cases with A775_G776ins12YVMA, three with 2326_2327insTGT, and one with 2331_2332 ins9 (ggctcccca), all of which are in exon 20. HER-2 inhibitors such as trastuzumab and afatinib were effective in inhibiting exon 20 insertion mutations $[18,19]$, which are thus a useful biomarker for assessing the therapeutic efficacy of these inhibitors. 

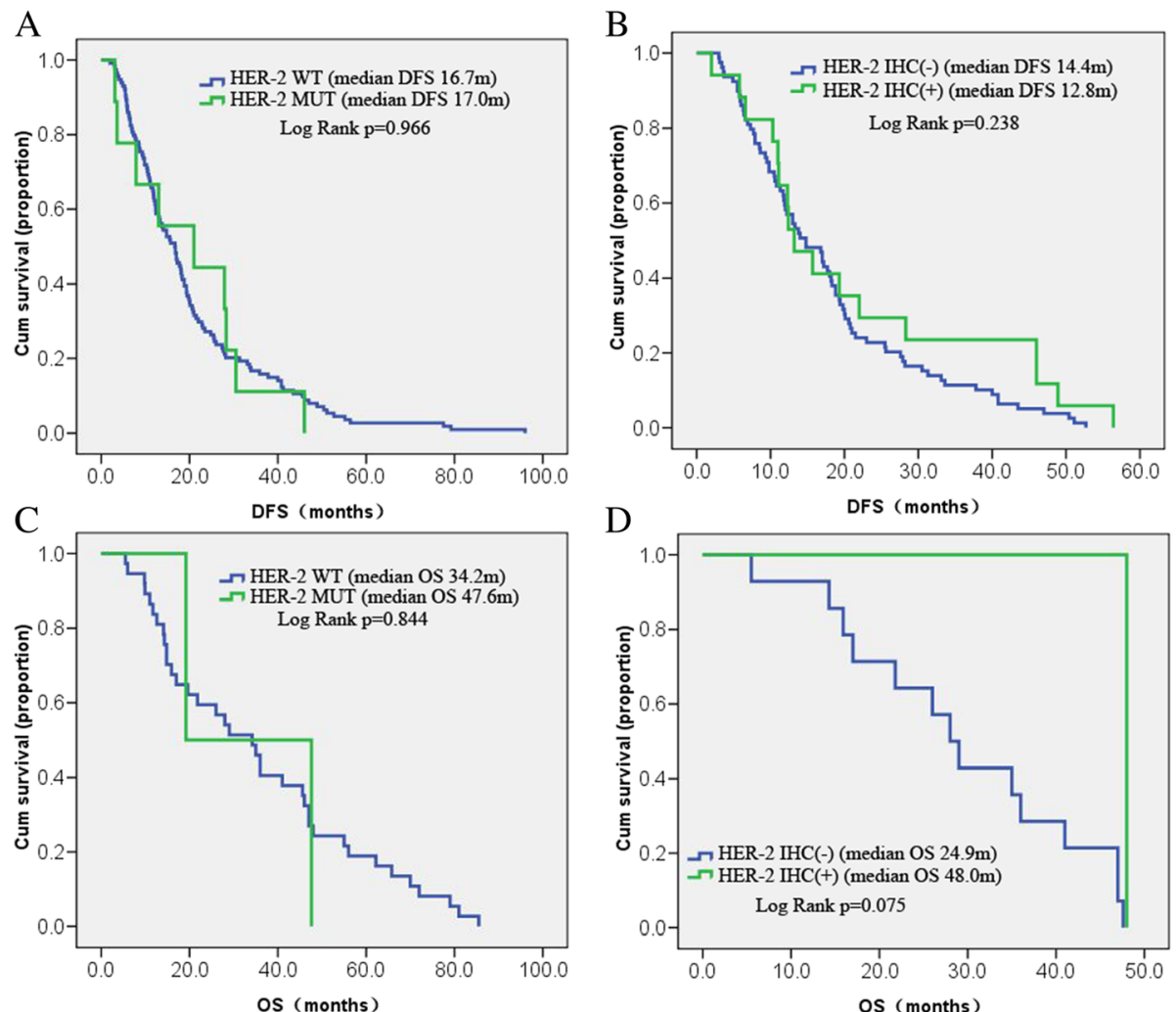

Fig. 5 DFS and OS were analyzed according to HER-2 mutations status and protein expression level, respectively. a DFS of HER-2 WT ( $n=114)$ and HER-2 MUT $(n=9)$ patients; b DFS of HER-2 IHC $(-)(n=79)$ and HER-2 IHC $(+)(n=17)$ patients; C. OS of HER-2 WT $(n=37)$ and HER-2 MUT $(n$ =2) patients; D. OS of HER-2 IHC (-) $(n=14)$ and HER-2 IHC $(+)(n=1)$ patients. WT: wild type group, MUT: mutation group; and HER-2 IHC (-): the score 0 or $1 ;$ IHC (+): The score 2 or 3

HER-2 mutations are more common in female nonsmokers with moderately to poorly differentiated adenocarcinoma, small tumor load, and early-stage lung cancer, but are not linked to patient prognosis [10, 11, 17]. Two studies in the Chinese population also found that HER-2 mutations were prevalent in female non-smokers, but were not correlated with prognosis [10, 20], while a study from Taiwan found an association between HER-2 mutation and late stages of disease [8]. We did not observe a correlation between mutation status and patient characteristics such as gender, age, disease stage, smoking status, or prognosis.

APA and PPA subtypes of lung adenocarcinoma accounted for $65.7 \%$ of all cases examined in this study. These results are consistent with those reported by others; for instance, among Caucasians, HER-2 mutations were primarily observed in PPA, APA, SPA, and MPA [9], whereas another study found that mutation rates were higher in PPA, AIS/MPA, LPA, and SPA [11]. Thus, HER-2 mutations are mainly associated with APA, PPA, IMA, SPA, and MIA subtypes with some similarity across ethnic groups; HER-2 inhibitors may be effective in such patients. Therefore, more emphasis should be placed on the classification of lung adenocarcinoma histological subtypes and HER-2 mutation analysis in clinical settings.

\section{Conclusions}

In summary, this study showed that HER-2 mutation was not correlated to HER-2 protein overexpression, and existing follow-up data did not show a correlation between HER-2 mutation with DFS or OS.

\section{Additional file}

Additional file 1: Figure S1. DFS of HER-2 $\mathrm{HCC}(-) /(+)$ patients in stage I/II and III/IV. A. DFS of HER-2 IHC (-) $(n=45)$ and IHC $(+)(n=10)$ patients in stage I/II. B. DFS of $\mathrm{IHC}(-)(n=31)$ and $\mathrm{IHC}(+)(n=6)$ patients in stage III/IV. (TIF $1145 \mathrm{~kb})$

\section{Abbreviations}

AIS: Adenocarcinoma in situ; ALK: Anaplastic lymphoma kinase; APA: Acinar predominant adenocarcinoma; ARMS: Amplification-refractory mutation system; DFS: Disease-free survival; EA: Enteric adenocarcinoma; EGFR: Epidermal growth factor receptor; HER-2: Human epidermal growth factor receptor-2; IMA: Invasive mucinous adenocarcinoma; LPA: Lepidic predominant adenocarcinoma; MIA: Minimally invasive adenocarcinoma; MPA: Micropapillary predominant adenocarcinoma; NSCLC: Non-small cell 
lung cancer; OS: Overall survival; PPA: Papillary predominant adenocarcinoma; ROS1: ROS proto-oncogene 1; SPA: Solid predominant adenocarcinoma

\section{Acknowledgements}

We thank Dr. Chunyan Wu and Dr. Dongmei Lin for the histologic subtype analysis.

\section{Funding}

The study was supported by research grants from Boehringer Ingelheim (China, Protocol No. 1200.192) and grants from the National Natural Science Foundation of China (No. 81401890, No.81372392, No. 81402486).

\section{Availability of data and materials}

The datasets supporting the conclusions of this article are included within the article.

\section{Authors' contributions}

$\mathrm{XL}$ and $\mathrm{CZ}$ contributed equally in preparing and conducting this research CS, SR and XC provided the patient information and followed the patient survival data. CZ designed and coordinated the research in the whole process. All authors read and approved the final manuscript.

\section{Competing of interest}

The authors declare that they have no competing interests.

\section{Consent for publication}

Not applicable.

\section{Ethics approval and consent to participate}

The study protocol was approved by the Ethical Review Committee of the Shanghai Pulmonary Hospital. Written informed consent was obtained from the patient for publication of this report and any accompanying tables and images.

\section{Author details}

${ }^{1}$ Department of Lung Cancer and Immunology, Shanghai Pulmonary Hospital, Tongji University, No. 507 Zhengmin Road, Shanghai 200433, People's Republic of China. ${ }^{2}$ Department of Medical Oncology, Shanghai Pulmonary Hospital, Tongji University Medical School Cancer Institute, Tongji University School of Medicine, No. 507 Zhengmin Road, Shanghai 200433, People's Republic of China.

Received: 25 May 2016 Accepted: 24 October 2016

Published online: 28 October 2016

\section{References}

1. Graus-Porta D, Beerli RR, Daly JM, Hynes NE. ErbB-2, the preferred heterodimerization partner of all ErbB receptors, is a mediator of lateral signaling. EMBO J. 1997;16(7):1647-55.

2. Oxnard GR, Binder A, Janne PA. New targetable oncogenes in non-small-cell lung cancer. J Clin Oncol. 2013;31(8):1097-104.

3. Alimandi M, Romano A, Curia MC, Muraro R, Fedi P, Aaronson SA, Di Fiore PP, Kraus $\mathrm{MH}$. Cooperative signaling of ErbB3 and ErbB2 in neoplastic transformation and human mammary carcinomas. Oncogene. 1995;10(9):1813-21.

4. Spector NL, Blackwell KL. Understanding the mechanisms behind trastuzumab therapy for human epidermal growth factor receptor 2-positive breast cancer. J Clin Oncol. 2009;27(34):5838-47.

5. Stephens P, Hunter C, Bignell G, Edkins S, Davies H, Teague J, Stevens C, O'Meara S, Smith R, Parker A, et al. Lung cancer: intragenic ERBB2 kinase mutations in tumours. Nature. 2004;431(7008):525-6.

6. Mazieres J, Peters S, Lepage B, Cortot AB, Barlesi F, Beau-Faller M, Besse B, Blons H, Mansuet-Lupo A, Urban T, et al. Lung cancer that harbors an HER2 mutation: epidemiologic characteristics and therapeutic perspectives. J Clin Oncol. 2013;31(16):1997-2003.

7. Sholl LM, Aisner DL, Varella-Garcia M, Berry LD, Dias-Santagata D, Wistuba II, Chen H, Fujimoto J, Kugler K, Franklin WA, et al. Multi-institutional oncogenic driver mutation analysis in lung adenocarcinoma: the lung cancer mutation consortium experience. J Thorac Oncol. 2015;10(5):768-77.

8. Hsu KH, Ho CC, Hsia TC, Tseng JS, Su KY, Wu MF, Chiu KL, Yang TY, Chen $\mathrm{KC}$, Ooi $\mathrm{H}$, et al. Identification of five driver gene mutations in patients with treatment-naive lung adenocarcinoma in Taiwan. PloS One. 2015;10(3):e0120852.

9. Arcila ME, Chaft JE, Nafa K, Roy-Chowdhuri S, Lau C, Zaidinski M, Paik PK, Zakowski MF, Kris MG, Ladanyi M. Prevalence, clinicopathologic associations, and molecular spectrum of ERBB2 (HER2) tyrosine kinase mutations in lung adenocarcinomas. Clin Cancer Res. 2012;18(18):4910-8.

10. Li C, Sun Y, Fang R, Han X, Luo X, Wang R, Pan Y, Hu H, Zhang Y, Pao W, et al. Lung adenocarcinomas with HER2-activating mutations are associated with distinct clinical features and HER2/EGFR copy number gains. J Thorac Oncol. 2012;7(1):85-9.

11. Suzuki M, Shiraishi K, Yoshida A, Shimada Y, Suzuki K, Asamura H, Furuta K Kohno T, Tsuta K. HER2 gene mutations in non-small cell lung carcinomas: concurrence with Her2 gene amplification and Her2 protein expression and phosphorylation. Lung Cancer. 2015;87(1):14-22.

12. Grob TJ, Kannengiesser I, Tsourlakis MC, Atanackovic D, Koenig AM, Vashist YK, Klose H, Marx AH, Koops S, Simon R, et al. Heterogeneity of ERBB2 amplification in adenocarcinoma, squamous cell carcinoma and large cell undifferentiated carcinoma of the lung. Mod Pathol. 2012;25(12):1566-73.

13. Hirsch FR, Varella-Garcia M, Franklin WA, Veve R, Chen L, Helfrich B, Zeng C, Baron A, Bunn Jr PA. Evaluation of HER-2/neu gene amplification and protein expression in non-small cell lung carcinomas. Br J Cancer. 2002; 86(9):1449-56.

14. Meert AP, Martin B, Paesmans M, Berghmans T, Mascaux C, Verdebout JM, Delmotte P, Lafitte JJ, Sculier JP. The role of HER-2/neu expression on the survival of patients with lung cancer: a systematic review of the literature. $\mathrm{Br}$ J Cancer. 2003:89(6):959-65.

15. Liu L, Shao X, Gao W, Bai J, Wang R, Huang P, Yin Y, Liu P, Shu Y. The role of human epidermal growth factor receptor 2 as a prognostic factor in lung cancer: a meta-analysis of published data. J Thorac Oncol. 2010;5(12):1922-32.

16. Takenaka M, Hanagiri T, Shinohara S, Kuwata T, Chikaishi Y, Oka S, Shigematsu Y, Nagata Y, Shimokawa H, Nakagawa M, et al. The prognostic significance of HER2 overexpression in non-small cell lung cancer. Anticancer Res. 2011:31(12):4631-6.

17. Tomizawa K, Suda K, Onozato R, Kosaka T, Endoh H, Sekido Y, Shigematsu $\mathrm{H}$, Kuwano H, Yatabe $Y$, Mitsudomi T. Prognostic and predictive implications of HER2/ERBB2/neu gene mutations in lung cancers. Lung Cancer. 2011:74(1):139-44.

18. Li BT, Lee A, O'Toole S, Cooper W, Yu B, Chaft JE, Arcila ME, Kris MG, Pavlakis N. HER2 insertion YVMA mutant lung cancer: Long natural history and response to afatinib. Lung Cancer. 2015;90(3):617-9.

19. Perera SA, Li D, Shimamura T, Raso MG, Ji H, Chen L, Borgman CL, Zaghlul S, Brandstetter KA, Kubo S, et al. HER2YVMA drives rapid development of adenosquamous lung tumors in mice that are sensitive to BIBW2992 and rapamycin combination therapy. Proc Natl Acad Sci U S A. 2009;106(2):474-9.

20. Bu S, Wang R, Pan Y, Yu S, Shen X, Li Y, Sun Y, Chen H. Clinicopathologic Characteristics of Patients with HER2 Insertions in Non-small Cell Lung Cancer. Ann Surg Oncol. 2016. [Epub ahead of print]

\section{Submit your next manuscript to BioMed Central and we will help you at every step:}

- We accept pre-submission inquiries

- Our selector tool helps you to find the most relevant journal

- We provide round the clock customer support

- Convenient online submission

- Thorough peer review

- Inclusion in PubMed and all major indexing services

- Maximum visibility for your research

Submit your manuscript at www.biomedcentral.com/submit
Biomed Central 